\title{
Communication
}

\section{Development of Tensile Properties and Crystalline Conformation of Recycled Polypropylene by Re-Extrusion Using a Twin-Screw Extruder with an Additional Molten Resin Reservoir Unit}

\author{
Patchiya Phanthong ${ }^{1, *(\mathbb{D})}$, Yusuke Miyoshi ${ }^{2}$ and Shigeru Yao ${ }^{1,2}$ \\ 1 Research Institute for the Creation of Functional and Structural Materials, Fukuoka University, \\ 8-19-1 Nanakuma, Jonan-ku, Fukuoka 814-0180, Japan; shyao@fukuoka-u.ac.jp \\ 2 Graduate School of Chemical Engineering, Fukuoka University, 8-19-1 Nanakuma, Jonan-ku, \\ Fukuoka 814-0180, Japan; td193012@cis.fukuoka-u.ac.jp \\ * Correspondence: patchiya@fukuoka-u.ac.jp; Tel.: +81-92-871-6631
}

Citation: Phanthong, P.; Miyoshi, Y.; Yao, S. Development of Tensile Properties and Crystalline Conformation of Recycled Polypropylene by Re-Extrusion Using a Twin-Screw Extruder with an Additional Molten Resin Reservoir Unit. Appl. Sci. 2021, 11, 1707. https://doi.org/10.3390/app11041707

Academic Editor: Faisal I. Hai

Received: 31 December 2020

Accepted: 11 February 2021

Published: 14 February 2021

Publisher's Note: MDPI stays neutral with regard to jurisdictional claims in published maps and institutional affiliations.

Copyright: (c) 2021 by the authors. Licensee MDPI, Basel, Switzerland. This article is an open access article distributed under the terms and conditions of the Creative Commons Attribution (CC BY) license (https:// creativecommons.org/licenses/by/ $4.0 /)$.
Featured Application: The specific application of this study was the establishment of a new unit added into the end of a twin-screw extruder, namely a "molten resin reservoir". The re-extrusion of recycled polypropylene by this modified twin-screw extruder was able to regenerate mechanical properties and a crystalline conformation similar to its virgin polypropylene.

\begin{abstract}
Plastic mechanical recycling is an attractive method for reducing the amounts of waste plastics. However, the alterations in the mechanical properties (degradation) in recycled plastics is a limitation to the material's mechanical recycling. In this study, the mechanical recycling was enhanced by the addition of a "molten resin reservoir" unit at the end of the twin-screw extruder. Recycled polypropylene (RPP) obtained from a household was re-extruded with this developed extrusion unit. The tensile properties, type of crystalline, and conformation of polypropylene polymorphs were evaluated and compared for virgin polypropylene (VPP), recycled polypropylene (RPP) without extrusion (RPP-original), and RPP with extrusion by using a new type of extruder (RPP-extrusion). It could be found that the tensile properties of RPP-extrusion were improved, so as to be similar to those of VPP. In addition, the conformation of RPP-extrusion was similar to that of VPP by increasing the ratio between the helix and parallel band. This study succeeded in regenerating the tensile properties and inner structures in recycled PP, which could prolong the used lifetime and decrease the amount of waste from single-use plastic.
\end{abstract}

Keywords: polypropylene recycling; recycled plastic; household plastic waste; polypropylene; twinscrew extrusion; tensile properties; crystalline conformation

\section{Introduction}

The consumption of plastic has greatly increased all over the world due to being used mostly in daily life. Single-use plastics have become the cause of environmental problems because they were disposed after one-time use and gathered on land and in the marine environment [1]. The degradation of plastics in the environment takes a very long time, i.e., decades to thousands of years [2]. For this reason, a suitable way for decreasing the amount of waste plastics is an attractive research subject in order to protect the future world environment.

Recycling is one of the processes that is able to decrease the amount of waste plastics. There were three main categories for plastic recycling; mechanical recycling, feedstock recycling, and energy recovery [3,4]. Among them, mechanical recycling was attractive because it was evaluated to have a high environmental performance from the life cycle assessment (LCA) evaluation. The use of a mechanical recycling approach can reduce $\mathrm{CO}_{2}$ 
emission, air emission with organic compounds, and waste production [5]. Mechanical recycling was carried out by the reprocessing of waste plastics with a mechanical method in order to produce new plastic products; however, the poor properties of the mechanically recycled products were an obstruction to the usage of mechanical recycling [6].

Extrusion is a mechanical process that is mainly used in plastic mechanical recycling. The degradation of recycled plastics in the extrusion process is caused by chain scission or the forming of cross-links [7,8]. From our previous work, it can be found that the degradation of plastics was not caused by chemical degradation but that the physical degradation was the main reason $[9,10]$. In addition, the suitable processing condition was able to improve the mechanical properties of plastics.

In order to decrease the effect from heat and shear of the extrusion process on the properties of plastics, the new additional unit connected at the end of the twin-screw extruder was established, namely as a "molten resin reservoir" [11]. The molten resin reservoir unit was the blank space connected between the end of the screws and the die. This blank space was controlled by the temperature, same as for the extrusion process. However, there was no shear stress from the screw rotation. As a result, the molten plastic products were relaxed from the shear stress by being kept in the blank space of the molten resin reservoir for a short time (40-60 s). Then, the extrudate came out from the die and cooled down to room temperature by water. Yao et al. [11] found that the elongation at break of unsorted recycled plastics extruded by the new type of twin-screw extruder with the additional molten resin reservoir unit was much more improved than for the conventional extrusion process. It is worth noting that the addition of the molten resin reservoir unit proved effective for the regeneration of properties in plastic products.

This study is the first to compare the mechanical properties and inner structures of virgin polypropylene (VPP) and recycled polypropylene (RPP) extruded by using a twin-screw extruder with an additional molten resin reservoir unit. The tensile properties, crystalline type, inner structure conformation, and molecular weight distribution were characterized by a tensile test, $X$-ray diffraction, infrared microscope, and high-temperature gel permeation chromatography. This study was expected to confirm the improvement in tensile properties and the changes of the inner structure of recycled polypropylene after re-extrusion by using a twin-screw extruder with an additional molten resin reservoir unit.

\section{Materials and Methods}

\subsection{Materials}

The VPP pellet (homo-polypropylene, F-300SP) was supplied by Prime Polymer Co., Ltd., Tokyo, Japan and was used without further purification. The RPP pellet originated from household plastic waste and was mainly separated into PP prior to being recycled as a pellet type at Toyama Kankyo Seibi Co., Ltd., Toyama, Japan. RPP, which was used without further processing, was identified as RPP-original. The photograph of the VPP and RPPoriginal pellet is shown in Figure 1a,b. In addition, the melt mass-flow rate and melting temperature of VPP and RPP-original are tabulated in Table 1. The melt mass-flow rate of RPP-original is slightly higher than VPP because of the difference in materials between virgin and recycled polypropylene. From the investigation of the melting temperature, RPP-original, which consisted of two melting peaks, could be attributed to the composition of polypropylene and polyethylene at a ratio of 4:1. On the other hand, VPP shows only one melting peak at $163.5^{\circ} \mathrm{C}$, which is the melting temperature of virgin polypropylene. 
(a)

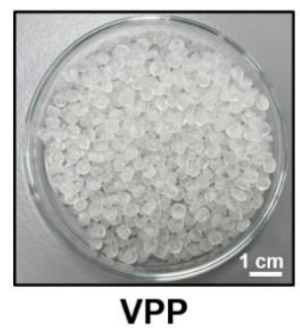

(b)

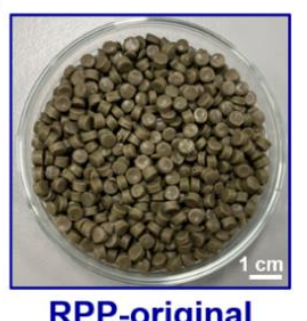

(c)

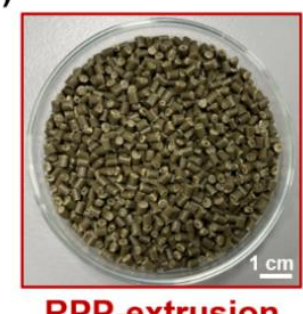

Figure 1. Photo images of the sample used in this study (a) VPP; (b) RPP-original; and (c) RPPextrusion.

Table 1. The melt mass-flow rate and melting temperature of VPP and RPP-original used in this study.

\begin{tabular}{ccc}
\hline Properties & VPP & RPP-Original \\
\hline Melt mass-flow rate $(\mathrm{g} / 10 \mathrm{~min})^{1}$ & 4.3 & 6.8 \\
Melting temperature $\left({ }^{\circ} \mathrm{C}\right)^{2}$ & 163.5 & $125.3,163.2$ \\
\hline
\end{tabular}

1 The melt mass-flow rate was characterized by a melt indexer (G-02, Toyo Seiki Seisaku-sho, Ltd., Tokyo, Japan) with the testing method of JIS K7210 at $230{ }^{\circ} \mathrm{C}$ and a weight of $2.16 \mathrm{~kg}$. ${ }^{2}$ The melting temperature was characterized by differential scanning calorimetry (DSC 8500, PerkinElmer Co., Ltd., Waltham, MA, USA). The measurement was operated under a nitrogen atmosphere in the range of -40 to $230{ }^{\circ} \mathrm{C}$ with 5 and $10{ }^{\circ} \mathrm{C} / \mathrm{min}$ of heating rate and cooling rate, respectively.

\subsection{Extrusion by Using a Twin-Screw Extruder with the Additional Molten Resin Reservoir}

RPP was reprocessed by using a twin-screw extruder (SBTN-26-S2, PLABOR Research Laboratory of Plastics Technology Co., Ltd., Osaka, Japan) with the additional molten resin reservoir unit, which was located at Fukuoka University, Fukuoka, Japan (Figure 2). The twin-screw extruder had a length/diameter (L/D) ratio of 60:1 with a screw length of $1560 \mathrm{~mm}$ and screw diameter of $26 \mathrm{~mm}$. The feed section was set at the position of $52 \mathrm{~mm}$ from the beginning of the screw length. The feed rate was controlled at $5 \mathrm{~kg} / \mathrm{h}$. The screw speed was controlled at $100 \mathrm{rpm}$, and the temperature of the screw was controlled at $230^{\circ} \mathrm{C}$.

Regarding the molten resin reservoir unit, which was connected to the end of the extruder, it was a blank space with a length of $355 \mathrm{~mm}$ and volume of $380 \mathrm{~cm}^{3}$. The material residence time inside the molten resin reservoir was around 40-60 s. The pressure was approximately around $0.5 \mathrm{MPa}$. The temperature in the molten resin reservoir unit was controlled so as to be the same as for the twin-screw extruder at $230^{\circ} \mathrm{C}$.

The extrudate came out from the die, which was connected to the end of the molten resin reservoir unit, and cooled to room temperature $\left(25^{\circ} \mathrm{C}\right)$ by water prior to being cut by the pelletizing machine with a take-up speed of $10 \mathrm{~m} / \mathrm{min}$.

The obtained pellet product was named RPP-extrusion. The photograph of the RPPextrusion pellet is displayed in Figure 1c.

\subsection{Injection Molding Process}

VPP, RPP-original, and RPP-extrusion pellets were molded in the shape of the tensile test specimen (JIS K7161 (1B)) by using an injection molding machine (J110AD 110H, the Japan steel works LTD., Tokyo, Japan). The injection molding condition was controlled at $200{ }^{\circ} \mathrm{C}$ with a $60 \mathrm{~mm} / \mathrm{s}$ injection speed. The molding time was $60 \mathrm{~s}$ with a packing time of $10 \mathrm{~s}$. The injection pressure was controlled at $70 \mathrm{MPa}$. The cooling temperature was at room temperature $\left(25^{\circ} \mathrm{C}\right)$. 
(a)
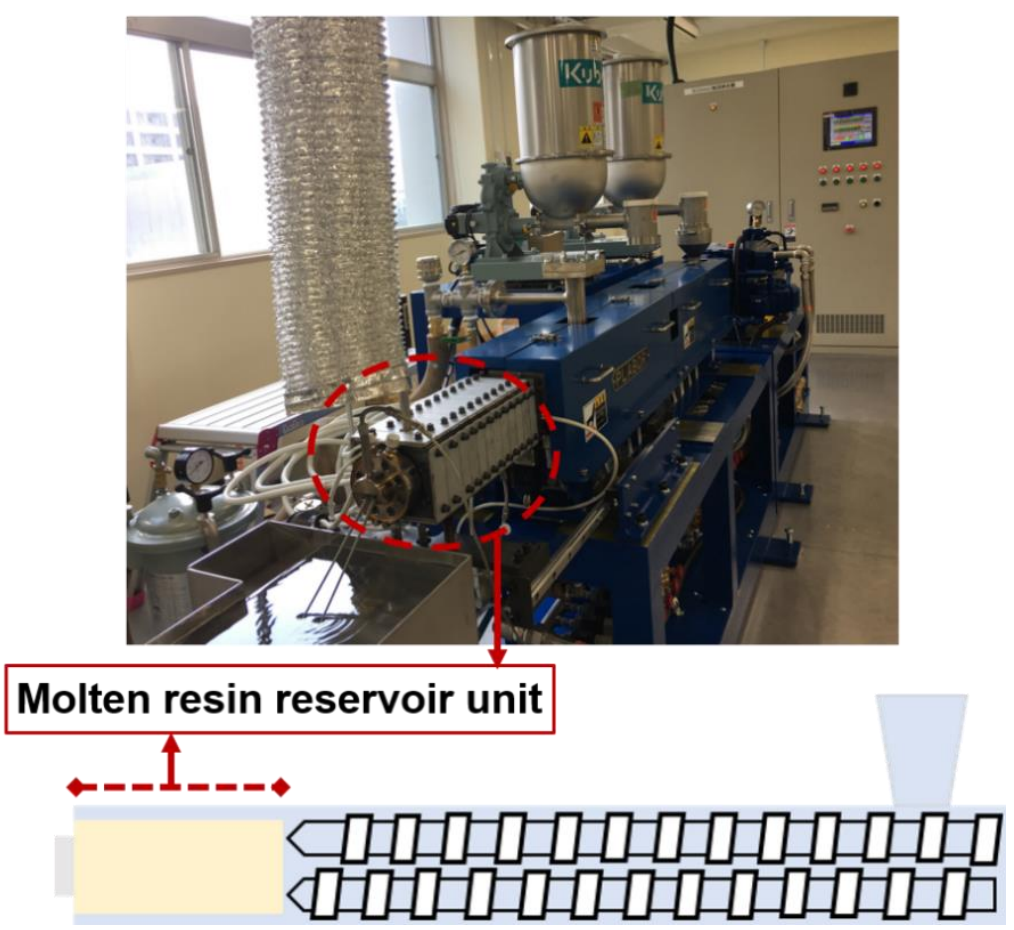

Figure 2. (a) Photo image of the twin-screw extruder with the additional molten resin reservoir unit; (b) Schematic image of the molten resin reservoir unit.

\subsection{Characterization}

The tensile properties were evaluated by using a universal material testing instrument (TENSILON RTF-1350, A\&D Co., Ltd., Tokyo, Japan) with a load cell of $10 \mathrm{kN}$. The tensile test was performed at a tensile speed of $50 \mathrm{~mm} / \mathrm{min}$ under atmospheric pressure with $25^{\circ} \mathrm{C}$ and $50 \%$ relative humidity. The tensile properties' values were averaged from five test specimens from each sample. The crystalline type was analyzed by X-ray diffractometer (XRD-6100, Shimadzu Corp., Kyoto, Japan). The scanning angle (20) was 10-40 degree with a scan speed of 2 degree/min. The X-ray source was obtained from a Cu X-ray tube, which operated at a 40-kV generator voltage and a 30-mA current. An infrared microscope (Thermo Scientific ${ }^{\mathrm{TM}}$ Nicolet $^{\mathrm{TM}} \mathrm{iN}^{\mathrm{TM}} 10$, Thermo Fisher Scientific Inc., Waltham, MA, USA) was used for the characterization of the infrared (IR) spectra and the mapping image of the ratio between the helix and parallel chain of the PP samples. The injection-molded samples were cross-sectionally cut with a thickness of $30 \mu \mathrm{m}$ prior to characterization at room temperature with a reflection mode. The molecular weight and polydispersity index were evaluated by high-temperature gel permeation chromatography (HLC-8321GPC/HT, Tosoh Corp., Tokyo, Japan) with a flow rate of $1 \mathrm{~mL} / \mathrm{min}$ at $140{ }^{\circ} \mathrm{C}$.

\section{Results and Discussion}

\subsection{Tensile Properties}

Figure 3 and Table 2 exhibit the tensile properties of VPP, RPP-original, and RPPextrusion. As compared to VPP, RPP-original showed low-value tensile properties. This can be attributed to the lower mechanical properties of RPP from the composition with PE (PP:PE = 4:1), in comparison with the high purity of polypropylene in VPP. On the other hand, the reprocessing by extrusion with the twin-screw extruder and the additional molten resin reservoir unit affected the significant regeneration of tensile properties in RPP-extrusion. As a result, RPP-extrusion exhibited tensile properties that were higher than RPP-original and similar to VPP. It is worth noting that the optimized extrusion condition and the additional molten resin reservoir unit had a role in increasing the tensile properties of recycled PP. 
(a)

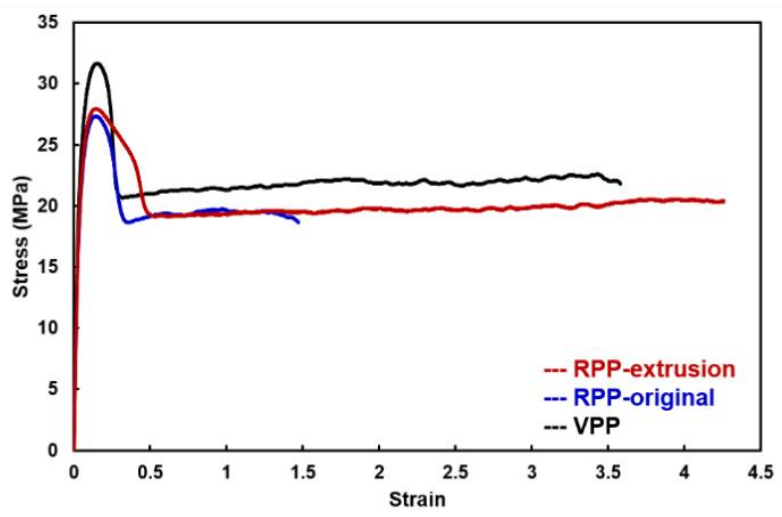

(b)

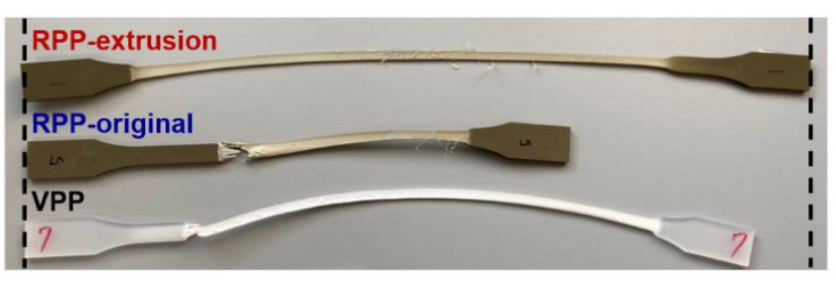

Figure 3. (a) Representative stress-strain curve of VPP, RPP-original, and RPP-extrusion; (b) Photo image of the elongated specimen after testing by tensile test.

Table 2. Tensile properties of VPP, RPP-original, and RPP-extrusion.

\begin{tabular}{cccc}
\hline Tensile Properties & VPP & RPP-Original & RPP-Extrusion \\
\hline Elongation at break $(\%)$ & $405.00 \pm 25.10^{1}$ & $282.46 \pm 32.34$ & $501.37 \pm 29.54$ \\
Toughness $\left(\mathrm{MJ} / \mathrm{m}^{3}\right)$ & $89.94 \pm 5.51$ & $57.92 \pm 7.03$ & $101.16 \pm 5.97$ \\
Yield stress $(\mathrm{MPa})$ & $31.53 \pm 0.27$ & $27.64 \pm 0.16$ & $27.88 \pm 0.05$ \\
Tensile fracture stress $(\mathrm{MPa})$ & $21.67 \pm 0.04$ & $19.30 \pm 0.28$ & $19.77 \pm 0.18$ \\
Young's modulus $(\mathrm{MPa})$ & $443.57 \pm 4.64$ & $387.34 \pm 3.90$ & $396.95 \pm 2.82$ \\
\hline
\end{tabular}

${ }^{1}$ The average values followed by the standard deviation.

\subsection{Crystalline Conformation}

In order to evaluate the crystalline type, XRD was used for characterization, and the profiles are displayed in Figure 4. The dominant crystalline structure in RPP was polypropylene, similar to VPP. The peak at $14.0^{\circ}, 16.8^{\circ}, 18.5^{\circ}, 25.4^{\circ}$, and $28.6^{\circ}$ of 2-theta, which was indicated at (110), (040), (130), (060), and (220) of the monoclinic crystal of i-PP in $\alpha$-form, appeared in all samples [12,13]. In addition, the trigonal crystals of i-PP in $\beta$-form were also detected at $16.0^{\circ}[12,14]$. The peaks at $21.5^{\circ}$ and $23.8^{\circ}$, which were indicated at (110) and (200) of the PE crystalline plane [15], were detected in the RPP samples. Furthermore, the diffraction peak at $27.5^{\circ}$ appeared for the RPP samples, which was indicative of talc particles [16] in the matrix of PP. It can be seen from the peaks in Figure 4 that the crystalline type of RPP-extrusion was similar to the RPP-original, even though the tensile properties were significantly improved.

The characterization by infrared microscope can define the chemical composition and the orientation of the crystalline and noncrystalline phases [17]. Figure 5a shows the IR spectra of VPP, RPP-original, and RPP-extrusion. The composition of the PP matrix $[18,19]$ was detected as being dominant for all samples; however, the characteristic peak of PE was detected in RPP samples at $721 \mathrm{~cm}^{-1}$, which was attributed to the rocking vibration [20]. In addition, there were no significant changes between the IR spectra of RPP-extrusion and $\mathrm{RPP}$-original, even though the tensile properties were different. 


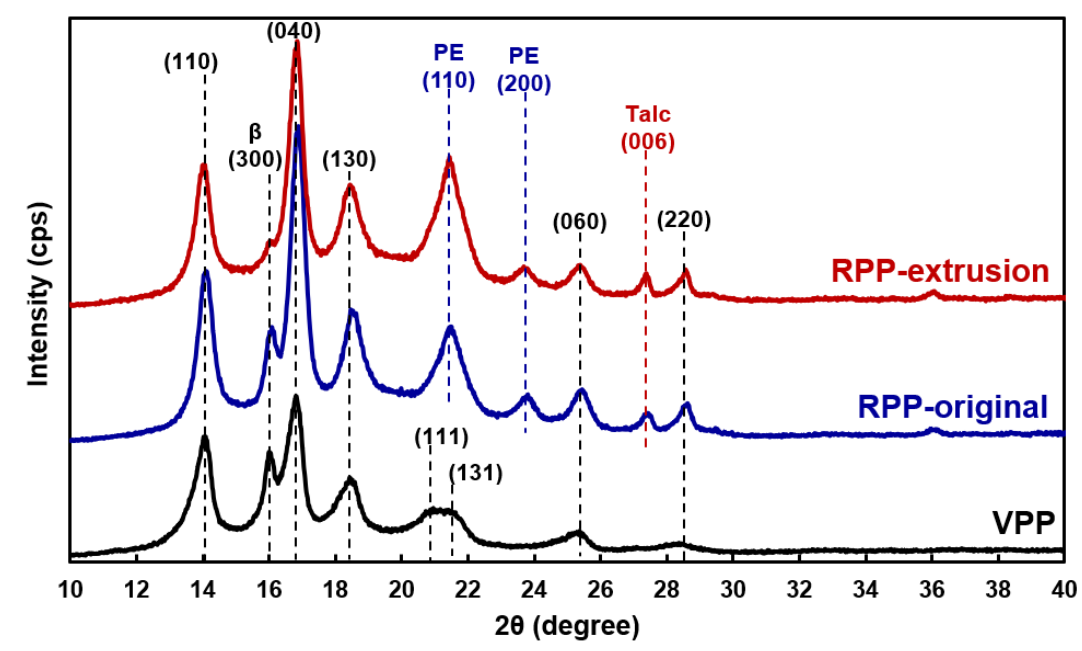

Figure 4. XRD profile of VPP, RPP-original, and RPP-extrusion.

(a)

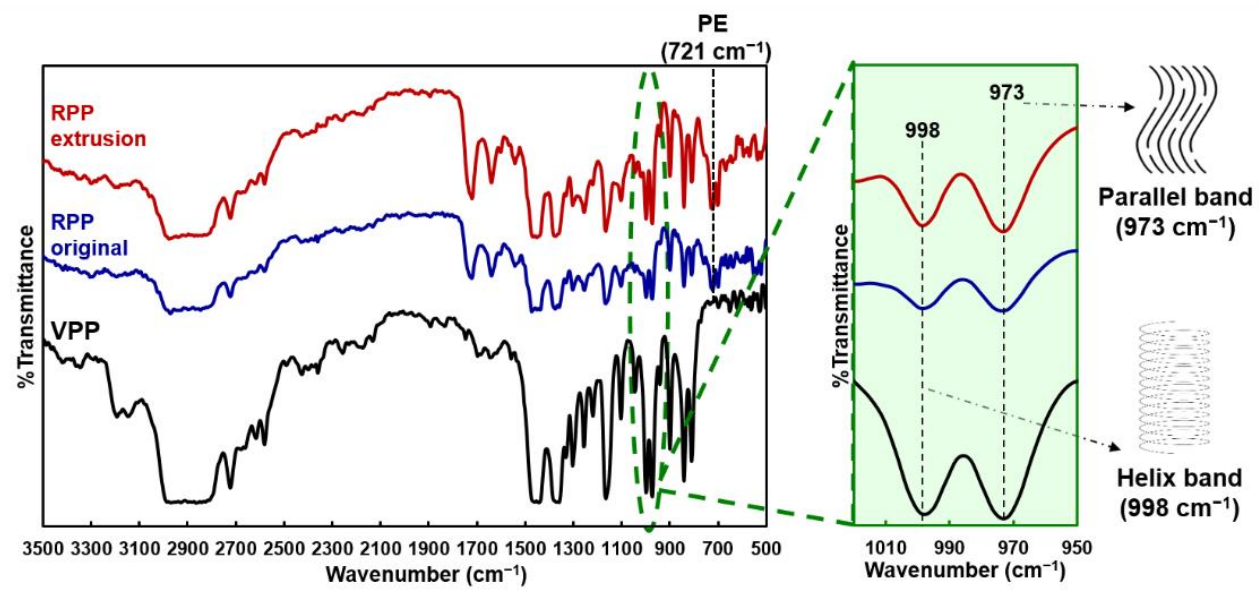

(b)

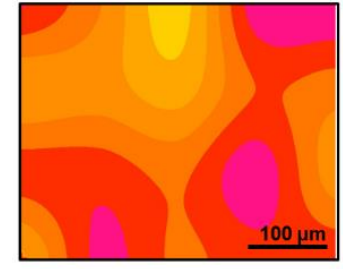

VPP

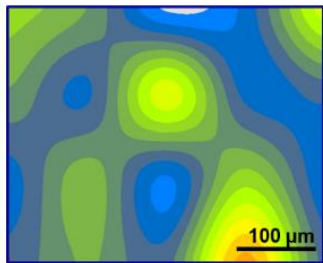

RPP-original

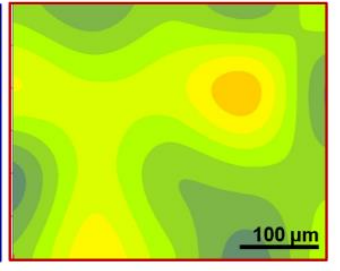

RPP-extrusion

Ratio of helix/parallel

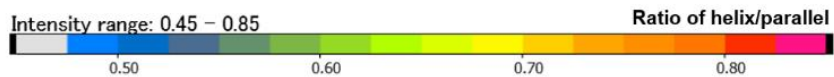

Figure 5. (a) IR spectra of VPP, RPP-original, and RPP-extrusion; (b) IR mapping for the ratio between the helix and parallel band.

It was attractive to focus on the conformation of PP in the helix band at $998 \mathrm{~cm}^{-1}$, which was a general conformation of PP polymorphs, and of the parallel band at $973 \mathrm{~cm}^{-1}$, which was defined by the shorter helix segments [21]. Figure 5b shows the IR mapping of the absorbance peak area ratio between $998 \mathrm{~cm}^{-1} / 973 \mathrm{~cm}^{-1}$ of the helix band/parallel band. VPP showed a high ratio range around $0.71-0.88$, which can be attributed to the high amount of helix band, which related to the good mechanical properties. Conversely, a low ratio was detected in RPP-original. This could be attributed to the high amount of parallel band in RPP-original, which affected the poor tensile properties in RPP. Interestingly, a slight increase of ratio occurred in RPP-extrusion at $0.56-0.71$. The helix bands of the PP conformation of RPP-extrusion were higher than for RPP-original, which could be 
related to the improvement of tensile properties, similar to VPP. Chen et al. [22] studied the correlation between the crystalline and amorphous orientations of isotactic polypropylene by FTIR imaging by monitoring characteristic peaks at $998 \mathrm{~cm}^{-1} / 973 \mathrm{~cm}^{-1}$. It could be confirmed that the deformation of spherulite was related to the ratio of crystalline and amorphous polypropylene.

\subsection{Molecular Weight Distribution}

High-temperature gel permeation chromatography (HT-GPC) was used to evaluate the molecular weight and molecular weight distribution of samples. Figure 6 showed the HT-GPC chromatogram of VPP, RPP-original, and RPP-extrusion. The peaks were detected around $25 \mathrm{~min}$ for all three samples. However, VPP showed a slightly different peak position due to the difference from RPP in the material composition. The detailed information of the molecular weight and molecular weight distribution is tabulated in Table 3. The number average molecular weight $(\mathrm{Mn})$, weight average molecular weight $(\mathrm{Mw}), \mathrm{Z}$ weight average molecular weight $(\mathrm{Mz})$, and polydispersity (Mw/Mn) of VPP were slightly higher than for RPP. It is worth noting that the molecular weight and molecular weight distribution of RPP-extrusion were similar to RPP-original. This can be attributed to the fact that re-extrusion by the twin-screw extruder with the additional molten resin reservoir did not affect changes in the chain length and chain structure of RPP. In addition, chemical degradation did not occur from the re-extrusion with the addition of the molten resin reservoir.

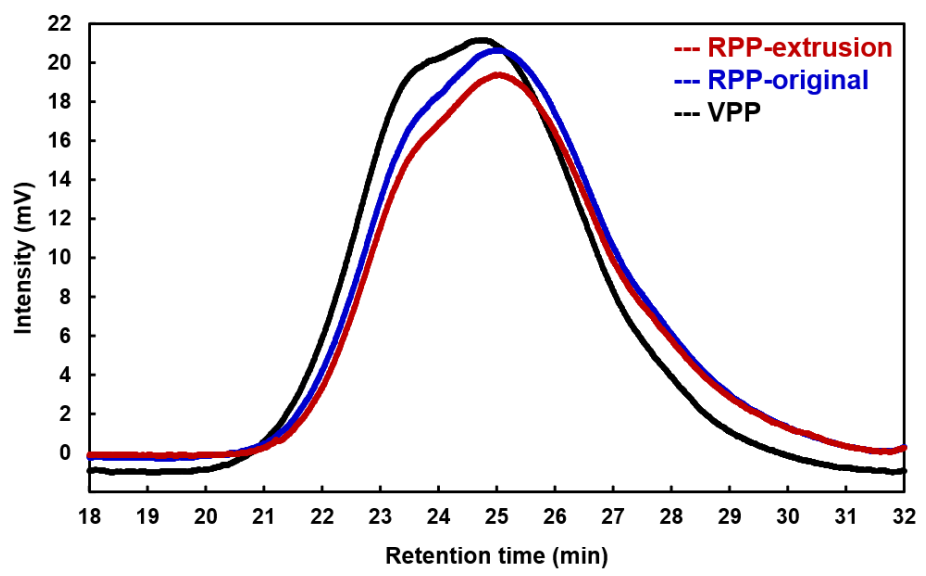

Figure 6. HT-GPC chromatogram of VPP, RPP-original, and RPP-extrusion.

Table 3. Molecular weight and molecular weight distribution of VPP, RPP-original, and RPP-extrusion.

\begin{tabular}{cccc}
\hline Molecular Weight (g/mol) & VPP & RPP-Original & RPP-Extrusion \\
\hline Mn & 117,323 & 85,678 & 83,900 \\
Mw & 529,233 & 385,345 & 377,513 \\
Mz & $1,857,035$ & $1,013,755$ & $1,044,314$ \\
Mw/Mn & 4.511 & 4.498 & 4.500 \\
\hline
\end{tabular}

\section{Conclusions}

By the use of a twin-screw extruder with the addition of a molten resin reservoir, one can improve the mechanical properties of recycled polypropylene (RPP). The elongation at break, toughness, yield stress, tensile fracture stress, and Young's modulus of RPP-extrusion was higher than for RPP-original and similar to VPP. By considering the crystalline conformation via the evaluation of the ratio between the helix and parallel band, RPP-extrusion showed an increase of the helix band when compared to its RPP-original, which could be attributed to the improvement of tensile properties. In addition, the molecular weight distribution of RPP-extrusion was similar to RPP-original, which could be 
attributed to the fact that re-extrusion by the twin-screw extruder with the additional molten resin reservoir did not affect changes in the chain length and chain structure of RPP. This study proved successful in improving the tensile properties in recycled PP, which can be further enhanced with other types of plastic.

Author Contributions: Conceptualization, P.P. and S.Y.; methodology, P.P. and S.Y.; validation, P.P. and S.Y.; formal analysis, P.P. and S.Y.; investigation, P.P. and Y.M.; data curation, P.P. and Y.M.; writing-original draft preparation, P.P.; writing — review and editing, P.P.; supervision, S.Y.; project administration, S.Y.; funding acquisition, S.Y. All authors have read and agreed to the published version of the manuscript.

Funding: This research was supported by the New Energy and Industrial Technology Development Organization (NEDO; JPNP20012) and the Environment Research and Technology Development fund (3-1705) of Environmental Restoration and Conservation Agency, Japan.

Institutional Review Board Statement: Not applicable.

Informed Consent Statement: Not applicable.

Data Availability Statement: No new data were created or analyzed in this study. Data sharing is not applicable to this article.

Conflicts of Interest: The authors declare no conflict of interest.

\section{References}

1. Pakhomova, S.; Zhdanov, I.; van Bavel, B. Polymer type identification of marine plastic litter using a miniature near Infrared spectrometer (microNIR). Appl. Sci. 2020, 10, 8707. [CrossRef]

2. Chamas, A.; Moon, H.; Zheng, J.; Qiu, Y.; Tabassum, T.; Jang, J.H.; Abu-Omar, M.; Scott, S.L.; Suh, S. Degradation rates of plastics in the environment. ACS Sustain. Chem. Eng. 2020, 8, 3494-3511. [CrossRef]

3. Plastic Waste Management Institute. An Introduction to Plastic Recycling. 2019. Available online: http://www.pwmi.or.jp/ei/ plastic_recycling_2019.pdf (accessed on 31 December 2020).

4. Alassali, A.; Picuno, C.; Bébien, T.; Fiore, S.; Kuchta, K. Validation of near infrared spectroscopy as an age-prediction method for plastics. Resour. Conserv. Recycl. 2020, 154, 104555. [CrossRef]

5. Perugini, F.; Mastellone, M.L.; Arena, U. A life cycle assessment of mechanical and feedstock recycling options for management of plastic packaging wastes. Environ. Prog. 2005, 24, 137-154. [CrossRef]

6. Ragaert, K.; Delva, L.; Geem, K.V. Mechanical and chemical recycling of solid plastic waste. Waste Manag. 2017, 69, 24-58. [CrossRef] [PubMed]

7. Santos, A.S.F.; Agnelli, J.A.M.; Trevisan, D.W.; Manrich, S. Degradation and stabilization of polyolefins from municipal plastic waste during multiple extrusions under different reprocessing conditions. Polym. Degrad. Stabil. 2002, 77, 441-447. [CrossRef]

8. Schyns, Z.O.; Shaver, M.P. Mechanical Recycling of Packaging Plastics: A Review. Macromol. Rapid Commun. 2020, 2000415, 1-27. [CrossRef]

9. Tominaga, A.; Sekiguchi, H.; Nakano, R.; Yao, S.; Takatori, E. Advanced recycling process for waste plastics based on physical degradation theory and its stability. J. Mater. Cycles Waste Manag. 2019, 21, 116-124. [CrossRef]

10. Takenaka, N.; Tominaga, A.; Sekiguchi, H.; Nakano, R.; Takatori, E.; Yao, S. Creation of advanced recycle process to waste container and packaging plastic-polypropylene sorted recycle plastic case. J. Soc. Rheol. Jpn. 2017, 45, 139-143. [CrossRef]

11. Yao, S.; Yamasaki, N.; Phanthong, P.; Yamashita, K.; Ueno, Y.; Michiue, T.; Takatori, E. Novel material recycle process based on the physical degradation and physical regeneration theory. In Proceedings of the international conference on advanced and applied petroleum, petrochemicals, and polymers (ICAPPP2018), Bangkok, Thailand, 18-20 December 2018.

12. Machado, G.; Denardin, E.L.G.; Kinast, E.J.; Gonçalves, M.C.; de Luca, M.A.; Teixeira, S.R.; Samios, D. Crystalline properties and morphological changes in plastically deformed isotactic polypropylene evaluated by X-ray diffraction and transmission electron microscopy. Eur. Polym. J. 2005, 41, 129-138. [CrossRef]

13. Yang, H.S.; Kiziltas, A.; Gardner, D.J. Thermal analysis and crystallinity study of cellulose nanofibril-filled polypropylene composites. J. Therm. Anal. Calorim. 2013, 113, 673-682. [CrossRef]

14. Triantou, M.; Todorova, N.; Giannakopoulou, T.; Vaimakis, T.; Trapalis, C. Mechanical performance of re-extruded and aged graphene/polypropylene nanocomposites. Polym. Int. 2017, 66, 1716-1724. [CrossRef]

15. Furukawa, T.; Sato, H.; Kita, Y.; Matsukawa, K.; Yamaguchi, H.; Ochiai, S.; Siesler, H.W.; Ozaki, Y. Molecular structure, crystallinity and morphology of polyethylene/polypropylene blends studied by Raman mapping, scanning electron microscopy, wide angle X-ray diffraction, and differential scanning calorimetry. Polym. J. 2006, 38, 1127-1136. [CrossRef]

16. Wang, K.; Bahlouli, N.; Addiego, F.; Ahzi, S.; Rémond, Y.; Ruch, D.; Muller, R. Effect of talc content on the degradation of re-extruded polypropylene/talc composites. Polym. Degrad. Stab. 2013, 98, 1275-1286. [CrossRef] 
17. Mallapragada, S.K.; Narasimhan, B. Infrared spectroscopy in analysis of polymer crystallinity. In Encyclopedia of Analytical Chemistry; John Wiley \& Sons: Hoboken, NJ, USA, 2006; pp. 1-14.

18. Jung, M.R.; Horgen, F.D.; Orski, S.V.; Rodriguez, C.V.; Beers, K.L.; Balazs, G.H.; Jones, T.T.; Work, T.M.; Brignac, K.C.; Royer, S.J.; et al. Validation of ATR FT-IR to identify polymers of plastic marine debris, including those ingested by marine organisms. Mar. Pollut. Bull. 2018, 127, 704-716. [CrossRef] [PubMed]

19. Crešnar, K.P.; Zemljic, L.F.; Perše, L.S.; Bek, M. Effect of wood fiber loading on the chemical and thermo-rheological properties of unrecycled and recycled wood-polymer composites. Appl. Sci. 2020, 10, 8863. [CrossRef]

20. Pang, W.; Ni, Z.; Chen, G.; Huang, G.; Huang, H.; Zhao, Y. Mechanical and thermal properties of graphene oxide/ultrahigh molecular weight polyethylene nanocomposites. RSC Adv. 2015, 5, 63063-63072. [CrossRef]

21. Andreassen, E. Infrared and Raman spectroscopy of polypropylene. In Polypropylene: An A-Z Reference; Karger-Kocsis, J., Ed.; Kluwer Publishers: Dordrecht, The Netherlands, 1999; pp. 320-328.

22. Chen, W.; Li, X.; Liu, Y.; Li, J.; Zhou, W.; Chen, L.; Li, L. The spatial correlation between crystalline and amorphous orientations of isotactic polypropylene during plastic deformation: An in situ observation with FTIR imaging. Chin. J. Polym. Sci. 2015, 33, 613-620. [CrossRef] 